\title{
$20+r e d$
}

Zür bie Şerausgabe biefer lateinifकृen Grammatif Fann midh vidbts rechefertigen, als Das $\mathfrak{B u \phi}$ felbit, Daf̧er glaube th nide, ouf bie Borzugge berfelben aufmertfam mađen zu bủrfen. Der waḩre Squls mann weif und fiebte fo gut, als id es ifgm nur immer würbe fagen uno zeigen fỏnen, was im

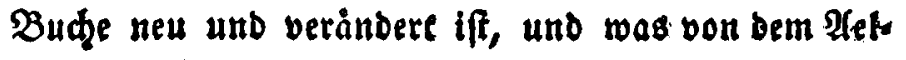

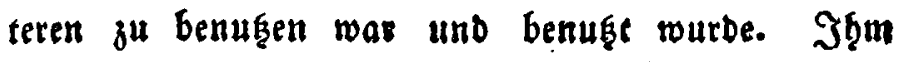
wird es feinesweges entgeb̧en, wie fich meine Gram= matil burd̨ zweftmåp̧igere Form und Anordinung ber Begenfănde, bon Den frůher, fủr Den Elementars Unterridget erfdzienenen, unterfḑeibet.

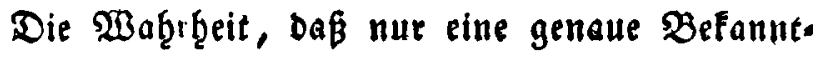
fḩaft mit bem etymologifḑen Ş̨eil einer Spradze, zur gründlid̨en Erlernung Derfelben füb̨ren Eonn, ift von jef̧er uno bon ben erfalgrenften Sdzulmän. nern fo oft und fo bringend ausgefproden worben, Daß̉ ein $\mathfrak{B e r f u \phi , ~ D e n ~ I ̂ n f a ̈ n g e r n ~ j e n e ~ u n e r l a p ̧ l i d ̨ e r ~}$ Borfennıniffe auf eine moglidgft zroefmảßige uno 
angenef̧me Meife odulig geläufig zu madzen, wenig: ften Eeinen Sabel gu berolenen fheint.

Bet einer Eleinen Baf̧l von Sqúlem ift bie

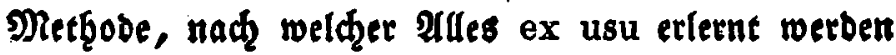
foll, woht anwenbbar; in iffentlidzen Shulen aber, wo in ben verfhiebenen Rlaffen inmer auf ben STrund ber früb̨er eingefanmesten, nađ̧ ber Şram: matif genau beftimmten uno georbneten Renntniffe, fortgebauet werben muß, bef̧àlt bas ftrenge $\mathfrak{A}$ sss wenbiglernen ber 9Darabigmata und bas mannigfals tigfte Innwenben berfelben, gewiß in ben meiften

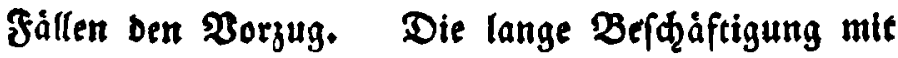
Den Formen, gemåg̨re freilth bem lebḩaften Beifte ber Jugend wenig Jreube; ber Infänger will gern iber bas troctene Feld ber Etymologie Gintwëg, unt wenbet auḑ ipàterb̧in, wenn ex bie Rúfen in feiner

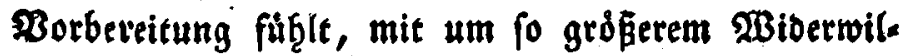
len feine Aufmerffamteit barauf, als bann ber Beit-

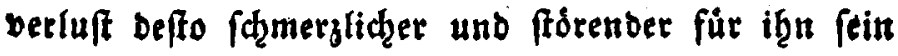

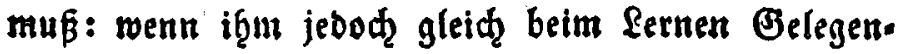
beit gegeben witb, Dasjenige, was er mit bem Ge. Dádztnißs auffaßste, anjuwenden, Mandzes aufjufinben und zu bilden, ja felbft feşlerb̧afte Ingaben zu ver: beffern, fo wiro ein grỏereres Intereffe bald bemerls bar, uno nád̨ft ber Siḑerḩeit im $\mathfrak{B i f f e n , ~ a u d z ~ D i e ~}$ Shărfung ber Beurtbeilungsfraft, - alfo ein Breet erreidzr, Den jeder gewillenţafte Sebrer bei allem un= terridżte, ftets im शluge beţalten follte.

Eollen ferner unfere Bỏglinge, wenn fie bie lateinifde Spradze anfangey, rafdze Fortfdritte 
madzen; foll ber freubige Eifer, ber bei allem Ser.

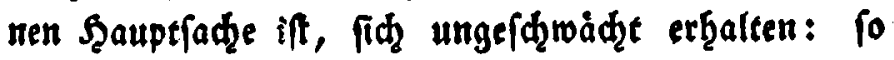

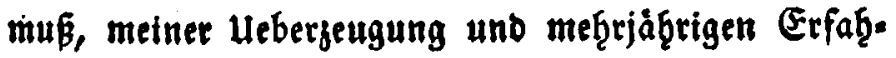
rung zufolge, bas Materiale ber Sprade mit Dem

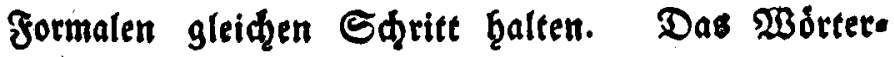

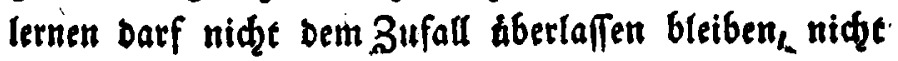

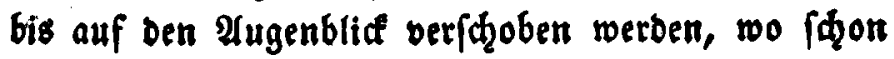
grósere Stưfe ůberfeģt werben follen; fonbern bie Shzùler múflen gleidzzeitig mit bem Erlernen uno Einúben ber Parabigmen unb bei bent Inwendent

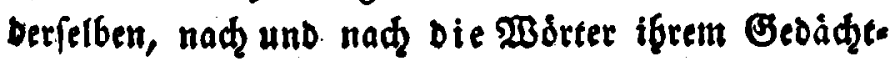
niffe cinpràgen, welḑe in ber Innenbung entḩaltek finb. Darum babe id aud jeber Iñwendung bie in Derfelben vorfommenten $\mathfrak{B}$ irter ḩingugefügt, uno

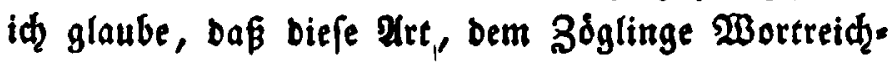

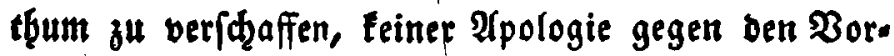

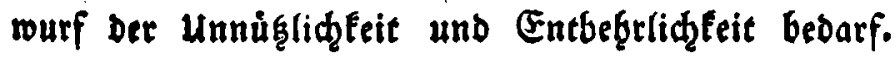

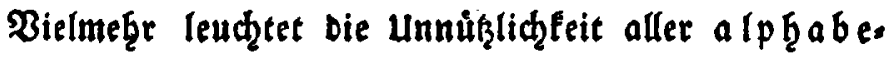

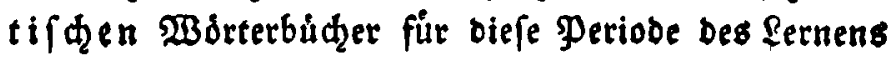
fo flar ein, Daß fidz, außer der leibigen Eewob̨n= beit und beun Sgerfommen. aus Den Beiten Des Pe: Dantismus uno Der Eprađ̧quálerei, Faum irgeno ei-

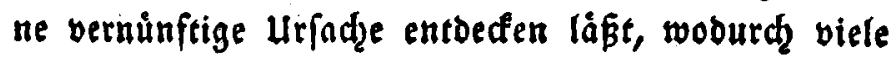
felbft würdige Miānner zu ber unnígen und ver. bienftlofen Bemúh̨ung bewogen wurben, iţre fonft vortrefflid̨en Rejebúd,er für bie Infänger in ber griedzifdzen, lateinifdzen ober franzdifdaen Spradze, mit einem, entweder oft mangelb̧aften, ober zu eis nem fo verberbliden Miß̧braud verleitenden $\mathfrak{A n}$. bange, als in biefem Falle ein alpb̧abetifh̨es $\mathfrak{B} d r$. 
terbuth offenbar iff, ju beglaiten: IAfe bie llebel, welde Der Gebraud eines alpḩabetifdzen buḑs Geerbeifüb̨rt, fatten weg, wenn bas

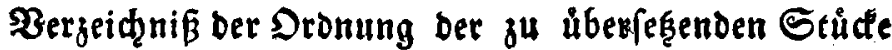
folgt, wofern nur ein zwedfmảßiger Gebraud bavon gemadzt wirb.

Seḩxer, von Muţ und Rraft für bas Reb̧rfach befeelt, ergreift Den Faben, Der Euth hiier in meis nem Eef̧rbudze gegeben wirọ! Bon bem Şauth ous lebendigen Seelen, erwartet ber tobte Budqftabe Beift und Reben. Durd Eud wird audg ber Beift in

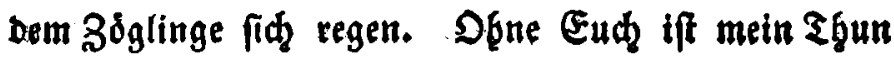
gering, burd, Eudh vermag es viel.

Berlin, im Ituguft 1825.

Э. そ. Cמafte. 